\begin{tabular}{|l|l|}
\hline $\begin{array}{l}\text { Guatemala, Estados Unidos y las ONGs: la desarticulación del Estado y el rol de la } \\
\text { asistencia }\end{array}$ & Titulo \\
\hline Romano, Silvina María - Autor/a; & Autor(es) \\
\hline $\begin{array}{l}\text { De Raíz Diversa. Revista Especializada en Estudios Latinoamericanos (Vol. 3 no. 5 } \\
\text { ene-jun 2016) }\end{array}$ & En: \\
\hline México D.F. & Lugar \\
\hline $\begin{array}{l}\text { Programa de Posgrado en Estudios Latinoamericanos, Universidad Nacional } \\
\text { Autónoma de México }\end{array}$ & Editorial/Editor \\
\hline 2016 & Fecha \\
\hline $\begin{array}{l}\text { Transición democrática; Neoliberalismo; Acuerdos de paz; Asistencialismo; } \\
\text { Organizaciones no gubernamentales; Guatemala; América Central; América Latina; } \\
\text { Estados Unidos; }\end{array}$ & Colección \\
\hline Artículo & Temas \\
\hline $\begin{array}{l}\text { "http://biblioteca.clacsoedu.ar/Mexico/ppel-unam/20160629044132/2._Guatemala_Estados_Unidos_y_las_oNGs__La_desarticulacion_d } \\
\text { el_Estado_y_el_rol_de_la_asistencia_silvina_M._Romano.pdr" }\end{array}$ & URL \\
\hline $\begin{array}{l}\text { Reconocimiento-No Comercial-Sin Derivadas CC BY-NC-ND } \\
\text { http://creativecommons.org/licenses/by-nc-nd/2.0/deed.es }\end{array}$ & Licencia \\
\hline
\end{tabular}
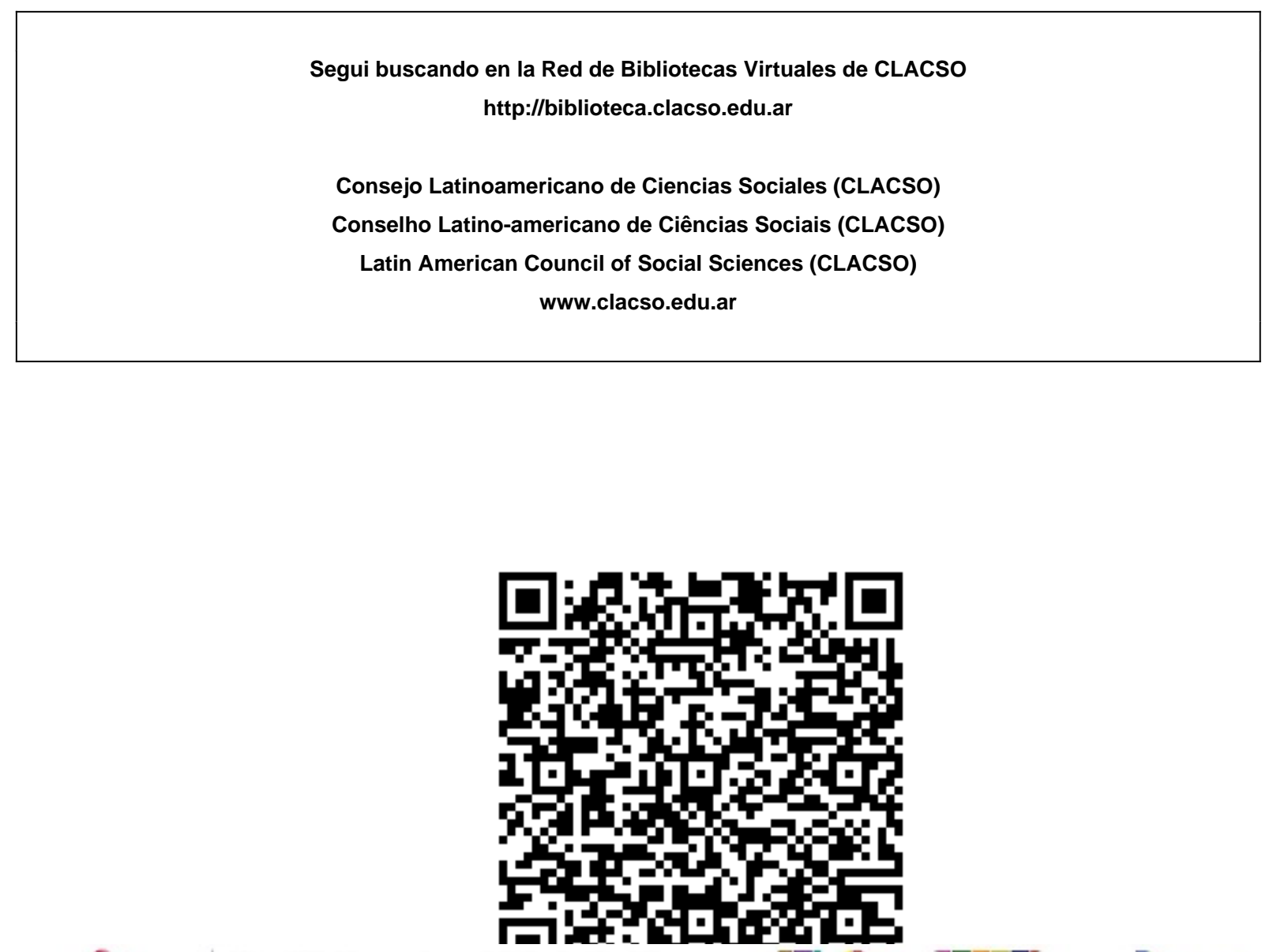

Consejo Latinoamericano de Ciencias Sociales

Conselho Latino-americano de Ciências Sociais

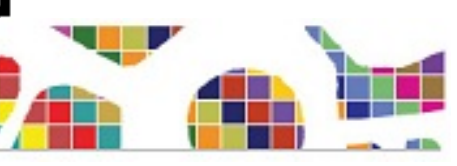




\section{Guatemala, Estados Unidos y las ONGs: La desarticulación del Estado y el rol de la asistencia}

Silvina M. RomANO*

ReSumen: En el marco de la Guerra Fría, la asistencia técnica y económica fue utilizada por el gobierno y el sector privado estadounidense (y por los organismos instituidos en Bretton Woods) como una estrategia de expansión de mercados y como herramienta capaz de reforzar la alineación de los Estados periféricos con respecto al bloque Occidental. En el caso de Guatemala, esta asistencia constituyó el eje para la "reconstrucción" del gobierno luego del derrocamiento de Arbenz en 1954, en detrimento de las reformas implementadas por los "gobiernos revolucionarios". Luego de los Acuerdos de Paz, en el marco de la neoliberalización de la región, la asistencia adquiere vigor en la nueva reconstrucción de las instituciones guatemaltecas. Muchas de las necesidades que debiera cubrir el Estado, han intentado ser cubiertas por ayuda para el desarrollo por parte de gobiernos extranjeros, empresas y ongs, mientras el Estado parece haberse reforzado (una vez más) en materia de seguridad ¿Qué intereses hay detrás de esta asistencia y qué dinámicas tiende a reproducir/cuestionar dentro de la lógica del mercado? ¿cómo se plantea la relación entre ongs en Guatemala y la red global de poder reforzada por el neoliberalismo? ¿en qué medida la "ayuda para el desarrollo" se vincula a la asistencia militar?

Palabras Clave: Guatemala, Asistencia, ONGs, Estados Unidos, red global de poder.

Abstract: Within the frame of the Cold War, economic and technical assistance was deployed by the United States private and public sectors, as well as by the Bretton Woods Institutions, in order to expand markets and to enhance the alliances between periphery countries and the Western Hemisphere. In Guatemala, this assistance was the corner stone for the reconstruction of the government after Arbenz overthrowing (1954), undermining the results of the reforms carried out by the "revolution governments". After the Peace Accords (1996), in the neoliberal atmosphere spread along Latin America, foreign assistance played a main role in the reconstruction of Guatemalan institutions. Many of the needs which should be solved by the state are rather covered by foreign assistance provided by governments, NGOs, corporations or private foundations. Meanwhile the state (once more) reinforces its "security" aspects. So ¿which are the

* Investigadora Asistente del Consejo Nacional de Investigaciones Científicas y Técnicas (CONiCET) en el Instituto de Estudios de América Latina y el Caribe (IEALC), Facultad de Ciencias Sociales, Universidad de Buenos Aires, Argentina <silvinamceleste@gmail.com>. 
interests behind this assistance? ¿there is any relation between the NGOs in Guatemala and the global power net shored by neoliberalism? ¿in which sense the economic assistance is bound to military assistance?

KeYWORDs: Guatemala, assistance, NGOs, United Sates, global power net.

Recibido: 22 de septiembre de 2015. ACEPTAdo: 12 de octubre de 2015 .

E

n este escrito buscamos aportar a la discusión sobre el rol de las Organizaciones No Gubernamentales (ONGs) en procesos-espacios en los que destaca la ausencia del Estado como garante de las necesidades socio-económicas de las mayorías, como el caso del Estado guatemalteco. Presentaremos un breve recorrido histórico sobre la asistencia estadounidense en Guatemala luego del derrocamiento de Jacobo Arbenz (1954) y su protagonismo en la "primera reconstrucción” del país. Luego nos remitiremos a la "segunda reconstrucción" de Guatemala pautada en los Acuerdos de Paz de 1996, destacando algunas de las metas que no pudieron ser logradas por un Estado débil en cuanto a la "cuestión social", dimensión que devino en el campo de acción de diversas ongs. Abordaremos específicamente las actividades de ONGs estadounidenses y brindaremos ejemplos que dan cuenta de la articulación de algunos de estos organismos con la red de poder global. Por último, damos cuenta del fortalecimiento del Estado en materia de seguridad, que aparece como "compatible" con la asistencia (tanto militar como para el "desarrollo"). De este modo, pretendemos contribuir a la visibilización de una red de poder global que tiende a ocultase, para brindar un panorama más completo de los intereses que pueden estar implicados en un asistencialismo aparentemente centrado en la buena voluntad. Este análisis concreto nos invita a cuestionar a nivel estructural el papel de la asistencia como mecanismo de reproducción de la dependencia económica y política.

\section{LA CONTRARREVOLUCIÓN Y LA PRIMERA RECONSTRUCCIÓN DE GUATEMALA}

La Revolución de Octubre ${ }^{1}$ es uno de los procesos que dieron cuenta en América Latina de la búsqueda de una democracia sustantiva en el marco

${ }^{1}$ En Guatemala se conoce como "revolución de octubre" o "20 de octubre" al movimiento cívico-militar ocurrido el 20 de octubre de 1944 que dio lugar a las primeras elecciones libres en ese país. 
del capitalismo de posguerra, una democracia centrada en el antiimperialismo, la participación política y la redistribución de recursos (Joseph, 2004; González Casanova, 1979). Los gobiernos de José Arévalo y Jacobo Arbenz fueron marcando el camino hacia la concreción de las metas definidas en la nueva Constitución de 1945: durante el primero se reguló la relación patrón-obrero mediante el Código de Trabajo; se instauró la Seguridad Social (Instituto de Seguridad Social de Guatemala), se promovieron campañas de alfabetización y el sistema de magisterio, se organizaron las instituciones básicas como el sistema de bancos, y se realizaron los primeros censos; se impulsaron actividades culturales y floreció la vida política con la organización de diversos partidos (aunque aquellos vinculados al comunismo luego fueron proscritos), se fortalecieron los sindicatos; se declaró la autonomía de la Universidad de San Carlos (Móbil, 2010; Guerra Borges, 2011).

A pesar de la inestabilidad política y de los múltiples intentos de golpe de Estado durante el gobierno de Arévalo, Jacobo Arbenz fue elegido presidente en 1951, constituyendo el primer traspaso de la banda presidencial por medio de elecciones libres y democráticas. Durante su gestión continuó con las reformas impulsadas por Arévalo, proponiendo una radicalización de las mismas a través de políticas de control de capital extranjero y particularmente, a través del plan y legislación de reforma agraria, que fue aprobada por el Congreso en junio de 1952 (decreto 900) previendo la "expropiación de extensiones de tierra mayores a 100 hectáreas, en especial tierras ociosas" (Cardoza y Aragón, 1955). En enero de 1953 comenzó a implementarse. La empresa estadounidense United Fruit Company (UFCO) tenía más de 220.000 hectáreas, de las que cultivaba sólo un 15\%. Para junio de 1954, habían sido afectadas 1002 plantaciones que abarcaban 1.200 .000 hectáreas; cerca de 100.000 familias campesinas recibieron tierras, créditos y ayuda técnica; además, el gobierno impulsó una campaña de alfabetización en el campo (Gleijeses, 1991: 155-161). Fueron expropiadas a la UFCO 160.000 hectáreas (Jonas 1979: 95-96). Si bien hubo quejas de diversos sectores de la sociedad por cada una de las reformas propuestas, y en particular se plantearon obstáculos económicos, políticos y raciales para la repartición de tierras (Handy, 1999); las medidas no solo fueron llevadas a cabo sino que generaron resultados positivos en términos de crecimiento económico. Otros proyectos fundamentales del gobierno fueron la construcción de la carretera al Atlántico para terminar con el monopolio de transporte de la UfCO-IRCA, la construcción de una 
hidroeléctrica para competir con la EEG (que era parte del mismo holding de la UfCO) y la construcción de otro puerto. Para estos emprendimientos se buscó la participación del capital privado estadounidense e incluso se solicitaron préstamos al gobierno de ese país, que fueron denegados.

Las elites locales, clases medias profesionales y la iglesia se opusieron duramente al proyecto arbencista, al que asociaron en buena medida a la "amenaza comunista". Esto fue aprovechado por el gobierno y sector privado estadounidense, que apoyaron a la oposición dentro y fuera de Guatemala mediante el Departamento de Estado y la ciA. Arbenz fue derrocado en junio de 1954 y el Coronel Castillo Armas (encargado del operativo de desestabilización y derrocamiento de Arbenz) asumió como presidente (Cullather, 2002; Schlesinger y Kinzer, 1982).

La contrarrevolución arrancó de raíz los avances en cuanto a democracia sustantiva. No sólo se anularon las medidas redistributivas, también las libertades políticas. El gobierno de Castillo Armas, carente de legitimidad, contó con el apoyo de parte de las Fuerzas Armadas y el gobierno estadounidense. Es fundamental señalar la presencia financiera, de asistencia técnica y "para el desarrollo" del sector privado (incluidas las fundaciones) y el sector público estadounidense para "reconstruir" Guatemala. Castillo Armas, notó que luego de la persecución y el exilio, ${ }^{2}$ ya no quedaba gente preparada para la administración pública. ${ }^{3}$ En este escenario, solicitó ayuda de modo explícito al gobierno estadounidense: "Necesitamos de la comprensión del pueblo estadounidense y de su gobierno. Necesitamos ayuda económica y asesoramiento técnico" (Congreso de Estados Unidos, Subcomité sobre América Latina, Comité sobre la Agresión Comunista de la Cámara Baja, septiembre-octubre 1954, 7).

Así comenzó la "reconstrucción" de Guatemala e ingresaron una cantidad de técnicos del país del Norte: de un mínimo de 10 empleados norteamericanos y 18 guatemaltecos, en julio de 1954, la misión de ayuda norteamericana en Guatemala aumentó a 165 personas -94 de ellas

\footnotetext{
2 Sobre la persecución y exilio de Guatemaltecos, ver: García Ferrerira, Roberto (2013) Bajo Vigilancia: La CIA, la policía uruguaya y el exilio de Arbenz (1957-60). Guatemala: Universidad de San Carlos, Guatemala, Centro de Estudios Urbanos y Regionales.

3 "Y le pregunté [a Castillo Armas] - ¿Cómo va su gobierno? y me dijo que se estaba desmoronando. Me dijo: - Ellos se llevaron a todos los que sabían leer y escribir. 'Ellos' eran los partidarios de Arbenz... lo que me estaba diciendo era 'todos los que podían y sabían llevar adelante un gobierno, todos son exiliados... y yo me quedé con la mierda"' (Henry Raymont en A Coup: Made In America. Documental escrito por Alan Mendelsohn y Nadine Pequeneza, puesto al aire en la serie de televisión canadiense "Turning Points of History" en 2001).
} 
eran ciudadanos norteamericanos- hacia mediados de 1959 (Jonas, 1974: 144). Para “organizar" institucionalmente al gobierno, si bien se tomaron iniciativas directas a través de la Administración para la Cooperación Internacional (ICA, predecesora de la Agencia Internacional para el Desarrollo), el gobierno norteamericano también se apoyó en otras dos agencias: el Banco Mundial y la consultora privada Klein \& Saks (K\&s) (Jonas, 1974: 144). ${ }^{4}$ Vemos que desde entonces existe la articulación entre sector privado y público, nacional e internacional, que ha ido conformando una red global de poder que no solo persiste en la actualidad sino que ha alcanzado proporciones insospechadas penetrando en espacios y organizaciones aparentemente "alternativas" al sistema. De hecho, fue entre mediados y finales de los '50 que se instalaron fundaciones y las primeras Organizaciones No Gubernamentales (aunque en aquella época no se denominaran de esta manera). ${ }^{5}$

La asistencia técnica para el desarrollo se profundizó con la Alianza para el Progreso en los ' $60,{ }^{6}$ en el contexto de surgimiento de las primeras guerrillas y las manifestaciones de las clases medias urbanas, estudiantes y sectores profesionales, reivindicando los logros de la Revolución de Octubre (Figueroa Ibarra, 1996) al calor de la efervescencia de la Revolución Cubana. La usAid (la Agencia Internacional para el Desarrollo del gobierno estadounidense) fungió como brazo operativo de la Alianza para el Progreso por medio de proyectos de alfabetización, preparación en liderazgo rural, construcción de viviendas, colonización -reubicación del campesinado- construcción de escuelas, caminos y pozos de agua, también organizó varios proyectos de cooperativas agrícolas (Streeter, 2006: 61). Pero a su vez, la USAID estuvo vinculada a las "acciones cívicas" de las Fuerzas Armadas a partir de mediados de los '60 y al entrenamiento en contrainsurgencia de la policía local, aspectos que luego se materializaron en la Doctrina de Seguridad Nacional, no solo en Guatemala sino en muchos países de América Latina (frus, 1961-1963. Vol xir. Doc. 90).

\footnotetext{
4 Este tema lo abordamos también en capítulo en prensa: "La asistencia como 'poder blando’ en la Guerra Fría: Estados Unidos y Guatemala (1954 -1963)” en García Ferreira, Roberto y Taracena Arriola, Arturo, Guerra Fría y anticomunismo en Centroamérica. Guatemala: Serviprensa. Con respecto a la ICA y la AID, es fundamental el rol que siguen teniendo en Guatemala, como podrá observarse en el apartado sobre ONGs en este mismo texto.

5 Más adelante se hará referencia a estos casos.

6 Sobre la Alianza para el progreso en América Latina, ver: Romano, 2013; Dreier, 1962.
} 
LOS ACUERDOS DE PAZ Y EL ESTADO NEOLIBERAL: LA SEGUNDA RECONSTRUCCIÓN DE GUATEMALA

Los Acuerdos de Paz sentaron las bases para la "reconstrucción" del Estado guatemalteco pero en el marco de una democracia procedimental que ya venía operando desde mediados de los '80, en un escenario en el que ya no había conflicto armado, aspecto que diferencia este caso de la gran mayoría de las negociaciones de Paz. De este modo, lo que se negoció en los Acuerdos fue el futuro desarrollo económico, social y político del país, más que el cese del fuego (Torres Rivas, 2006: 12). ${ }^{7}$ Según este intelectual guatemalteco, fueron cinco los principales ejes de los Acuerdos: La multietnicidad de la nación; el resarcimiento, la reconciliación y la identidad nacional; la desmilitarización del Estado y la sociedad; la protección jurídica, los derechos humanos y la impunidad; el combate por la justicia social (Torres Rivas, 2006: 32).

Con respecto al primer punto que implicaba la inclusión de los pueblos indígenas, a pesar de los importantes avances logrados, se trata de un problema grave, en tanto se unen irremediablemente clase y etnia en las cifras de miseria y exclusión: el Instituto Nacional de Estadísticas de Guatemala calculó para el 2006, que de un total de 12.978.829 habitantes, 6.625.892 eran (son) pobres, es decir, la mitad de la población guatemalteca (INE, 2006). El 74.8\% de estos pobres son indígenas. La mayoría de la población sigue viviendo en el campo y el régimen de tenencia de la tierra no se ha modificado sustancialmente, lo cual da cuenta de los escasos avances en cuanto a justicia social. Según el censo de 2003: "el $92 \%$ de las y los pequeños productores únicamente cultivan el $22 \%$ de la superficie, mientras el $2 \%$ de los productores comerciales ocupan el 56.59\% de la superficie. Existen 47 fincas de 3,700 hectáreas o más, mientras el $90 \%$ de los productores sobreviven con un promedio de una hectárea" (Barreda, 2007). A esto se suma la persecución y represión de las comunidades que reivindican la puesta en práctica de lo establecido en los acuerdos.

En lo referido a la subordinación de los militares a las fuerzas civiles, si bien se ha intentado mantener una cierta apariencia, el vínculo del ex presidente Otto Perez Molina a las ffaA, el resultado del juicio por genocidio al ex General Ríos Montt y las múltiples experiencias de

7 Para profundizar, ver Páez Montalbán, 1998. 
represión de la población civil a manos de las fuerzas armadas y policía ${ }^{8}$ dan cuenta de los lentos avances en términos de construcción de la memoria, resarcimiento y lucha por el respeto a los Derechos Humanos (lucha impulsada por la sociedad civil y boicoteada en buena medida desde el Estado, que como veremos en el último apartado, ha reforzado los mecanismos de represión).

A pesar de este escenario, el Banco Mundial sostiene que “...a partir de la Firma de los Acuerdos de Paz en 1996, Guatemala ha progresado en el fortalecimiento de sus instituciones y ha abierto las puertas a los mercados internacionales a través de diversos acuerdos comerciales" aunque se aclara que esto es acompañado por los peores indicadores de desarrollo social. Las cifras, correspondientes a 2011 son alarmantes, pues indican que la pobreza subió a un 53.7\%, y que la situación es especialmente complicada en los municipios rurales, que abarcan el $44 \%$ del país. Allí casi ocho de cada 10 personas viven en pobreza (Banco Mundial, 2015).

Se percibe entonces, que lo que sí se viene logrando con resultados no desdeñables, es la inserción de Guatemala en el mercado internacional (con mayores o menores reveses), en virtud de sus "ventajas comparativas", ${ }^{9}$ es decir, se han logrado importantes avances en la construcción de un Estado neoliberal. La inversión extranjera directa en Guatemala se ha incrementado en las últimas décadas, al igual que en Centroamérica en general, a pesar del escenario de violencia e inseguridad (que supuestamente debería ir en detrimento de las inversiones). En Guatemala, los sectores más dinámicos en relación a la Inversiòn Extranjera Directa (IED) los de servicios financieros, alimentos, minería, electricidad y telecomunicaciones (Central America Data, 2011). En el último año, se vienen incrementado las inversiones en el sector de infraestructura para transportes, pero en términos generales, los empresarios reclaman una

\footnotetext{
8 En este sentido, es fundamental el paso de ex militares a unidades policiales, la presencia de ex militares en agencias de seguridad privada; la asociación de ex kaibiles (fuerzas de operación especiales) con bandas de narcotráfico y la permanente relación con las fuerzas armadas estadounidenses en términos de entrenamiento e intercambio (sobre todo teniendo en cuenta la presencia del Comando Sur operando desde Honduras).

9 Este concepto es particularmente útil, pues desde las Instituciones Financieras Internacionales (IFIs) se sigue planteando el desarrollo desde una perspectiva neoclásica, claro está, a pesar de las numerosas críticas realizadas tanto desde la academia, como de las experiencias surgidas de la puesta en práctica de estas medidas en países periféricos (Ver: Blömstrom y Hettne, 1990; Prebisch, 1949).
} 
mayor "certeza jurídica", ${ }^{10}$ algo que va en consonancia con el mandato del mercado: "Los gobiernos deben entender que los inversionistas no arriesgan su dinero para desarrollar las economías receptoras. Lo arriesgan para ganar más dinero" (Central America Data, 2011b).

Lo anterior fue perfectamente captado por las metas de la Alianza para la Prosperidad firmada entre los países del Triángulo Norte de Centroamérica, que tiene como uno de sus corolarios conciliar el crecimiento económico (hacia fuera) con un escenario de seguridad y estabilidad mínimas. En la letra de este acuerdo se celebran las "reformas estructurales implementadas en los '90 y la mayor apertura del comercio, que permitieron un crecimiento de un 3.5\% anual en los países de la región entre 1990-2013" (BID, 2014: 3). A pesar de estos "logros", se presentan varios desafíos: bajar los costos de la electricidad y la logística, así como lograr un mayor acceso a internet para incrementar la inversión privada, que es lo que a su vez permitirá generar una fuerza de trabajo del Siglo xxi (Ibid, i; 5; 10); fortalecer los sectores estratégicos para atraer la inversión, que serían el textil, agroindustria, bienes de consumo y turismo (Ibid, 11); atraer inversión privada por medio de un esfuerzo conjunto para bajar costos en la producción de energía y mejorar la logística para un mercado integrado; agilizar la relación entre países, generando un marco regulatorio que permita el flujo de mercancías de modo rápido y con menor costo, permitiendo un control de fronteras eficiente, incluyendo aduanas, migración, controles de seguridad y salud, modernizando la infraestructura y los equipamientos para ello (Ibid, 13). Vale señalar aquí que es probable que el equipamiento y los servicios requeridos para esta "modernización" sean comprados a empresas de seguridad estadounidenses especializadas en el rubro (Delgado Ramos y Romano, 2010: 34). Estados Unidos ofrece a cambio de esta "modernización" tarifas preferenciales para productos centroamericanos (14). En este punto conviene observar las tradicionales medidas proteccionistas del Estado norteamericanos, así como la presión de la AFL-CIO con respecto a las condiciones y límites para los tratados de liberalización comercial.

Los mencionados lineamientos, a su vez, deben ir acompañados de un esfuerzo para luchar contra el narcotráfico y el crimen organizado, que implican también una modernización en el sistema impositivo y el manejo

10 Ver, por ejemplo: "Modernización portuaria por $\$ 80$ millones" http://www. centralamericadata.com/es/article/home/Modernizacin_portuaria_por_80_millones 
financiero. La justicia debe adecuarse al respeto a los DDHH, mejorar la vigilancia en las fronteras y el sistema de prisiones (BID, 2014: ii; 19). Para ello, será fundamental contar con la participación de "otros países aliados, organismos multilaterales y socios -partners- para el desarrollo" (Ibid, 22). Es aquí donde comienza a vislumbrarse un rol importante de la alianza ONGs-think tanks-fundaciones-sector público, como responsables de la modernización requerida. El documento también manifiesta la preocupación estadounidense por la creciente migración centroamericana hacia su país, y se sostiene que habría que atender las causas de la misma: "la falta de empleos bien remunerados, la ausencia de educación y oportunidades de empleo, la desnutrición, extrema pobreza, inequidad y el crimen" (Ibid, 2). Es curioso, porque estas condiciones son las mismas que los gobiernos de la Revolución Guatemalteca intentaron resolver, y no tuvieron tiempo real para hacerlo. Son las mismas cuestiones debatidas entre neoclásicos, cepalinos y dependentistas entre los ' 40 y los '70, que versaban sobre algunas cuestiones que se percibían en el devenir de las sociedades de América Latina: que la inversión extranjera, en lugar de crecimiento con igualdad genera extracción de excedentes e inequidad; que el Estado debe ser el responsable de las cuestiones sociales, pues no son rentables para el sector privado; que el Estado debe imponer reglas y restricciones para controlar flujos de capital y comerciales si se espera redistribuir riquezas e ingresos a favor de las mayorías y evitar la acumulación en sectores pudientes; que para ello es fundamental salir del patrón primario-exportador, apostando a diferentes grados de industrialización que permitan una menor dependencia del precio volátil de las commodities. Además, el tipo de rol adquirido por el Estado frente al sector privado determina las políticas de seguridad, en muchos casos derivadas en militarización y represión, para mantener un sistema desigual (ver: Prebisch, 1949; Caputo y Pizarro, 1975; Dos Santos, 1972 y 1975).

\section{LA ASISTENCIA Y LAS ONGS}

El escenario de miseria, corrupción y mala gestión da lugar a que la comunidad internacional siga apelando a la asistencia técnica para el desarrollo como vía para generar un cambio (alternativa que es aprovechada y explotada al máximo, tanto por el gobierno como por los intereses privados locales). Es importante señalar que la asistencia a nivel internacional se institucionaliza con los Acuerdos de Bretton Woods (1944), y se extiende 
en el contexto de Guerra Fría bajo el paradigma de la modernización (Mattelart y Mattelart, 1997) y el desarrollo "por etapas" (Rostow, 1962), que consolidaron y expandieron la idea de que la gente de los países centrales, civilizados, industrializados, podía (tenía una responsabilidad moral individual de) ayudar a las comunidades y personas atrasadas, incivilizadas. En este sentido, se reforzaron mecanismos de asistencia que paulatinamente mostraron su verdadera esencia: la consolidación de la dependencia por parte de países periféricos respecto de insumos, inversiones extranjeras, así como la incorporación de nuevas pautas de consumo (Romano, 2012; Barnet y Müller, 1974). Ante este escenario, los teóricos de la dependencia, marxistas latinoamericanos y los neomarxistas estadounidenses realizaron críticas contundentes con respecto a la politización de la asistencia (pública y privada) y su utilización para extorsionar y desestabilizar gobiernos. ${ }^{11}$

Con la desarticulación de las funciones sociales del Estado (o los mínimos avances en justicia social en países periféricos), la asistencia que había sido especialmente encarnada por agencias estatales y organismos internacionales, ${ }^{12}$ fue delegándose y ampliándose también a un nivel micro, es decir, comenzó a incorporar la ayuda de persona a persona o de una persona a una pequeña comunidad en asuntos puntuales, por medio de las ongs. Esto obedece, por un lado, a la crítica realizada a las mismas IFIs por las consecuencias negativas de los "ajustes estructurales" del tipo del Consenso de Washington (hacia allí apuntaban las críticas de economistas liberales como Stiglitz e incluso los "Objetivos del Milenio" de la onu). Por otro lado, da cuenta de la deslegitimación, por parte de la comunidad internacional, del Estado como ente capaz de redistribuir recursos de modo adecuado, tarea que aparentemente, sería llevada a cabo de mejor manera por el "tercer sector". Así es que las ONGs adquirieron visibilidad en el contexto de la neoliberalización de América Latina, especialmente a partir de los '90. Estos organismos se presentan en términos legales como organizaciones sin fines de lucro, y se definen por no pertenecer al ámbito de lo público. Más allá de las diversas misiones que se proponen cumplir, su existencia se justifica para cubrir (mínimamente) los vacíos dejados por la escasa presencia del Estado en cuestiones sociales en la periferia, sumado a múltiples factores sociales

11 Barnet, 1974; Cotler y Fagen, 1973; Caputo y Pizarro, 1975. Ejemplos concretos, la desestabilización del gobierno de Goulart en Brasil, Allende en Chile (Romano, 2012b: 151, 155, 159).

12 Para la "tercerización” de la asistencia, ver: Martins 1973, Guess, 1987. 
y culturales que se desarrollaron en los países centrales (mayor tiempo libre, mayor longevidad luego de la jubilación, etc.).

Puede hablarse largamente de la función de las ONGs, pero aquí nos remitiremos a cuestiones básicas. La primera, es que el Estado es por principio, responsable ante sus ciudadanos, mientras que las oNGs lo son ante sus donantes. Si se tiene en cuenta el contexto de su surgimiento y "reproducción", muchas ONG han sido útiles y todavía lo son, para degradar y descalificar al Estado (por incompetente, corrupto, fallido, etc.). Para diferenciarse de ese Estado, las ONGs trabajan en proyectos concretos con gente concreta, focalizando los esfuerzos, logrando resultados "visibles" (que puedan ponerse a disposición de los donantes, para demostrar la importancia de sus aportes a las vidas de gente de carne y hueso). Este modus operandi ha sido también rescatado por parte de la izquierda, que ya no se fía de reformas y redistribuciones realizadas por el Estado, que tampoco busca una revolución para cambiar las estructuras, sino que "se conforma" con cambios inmediatos aunque sean de escasísimo alcance. Así, uno de los efectos de la creciente presencia de ONGs es el de despolitizar la lucha y cooptar a líderes e intelectuales de izquierda (Petras, 1999: 429).

El rol de las ONGs es especialmente sugerente en sociedades "posconflicto". Precisamente hacia finales de los '90, se profundizó la discusión sobre el rol de los organismos internacionales, las fundaciones y ONGs en los procesos de paz y la reconstrucción en Centroamérica (entre otros; Sollis, 1995; Pearce, 1999; Jonas, 2000; Gerson, 2001; Blum, 2001) -hacemos un paréntesis para repetir que en el caso de Guatemala, la discusión sobre los Acuerdos de Paz fue más bien orientada hacia la cuestión de la democracia y el desarrollo (y aun así, no se prestó suficiente atención al contexto neoliberal que condicionaba las metas propuestas), pues el conflicto armado ya había cesado años atrás. En el marco de esta discusión, algunos de los aportes se centraron en la relación entre los procesos micro y la estructura de un sistema capitalista cada vez más financiarizado y tendiente a una concentración aún mayor de recursos, riquezas, etc. en determinados sectores de la economía y las elites mundiales. El hecho es que en la mayoría de los procesos, la comunidad internacional, en lugar de presionar a las elites y las clases políticas locales a encarar una serie de medidas tendientes a la redistribución, tendió a brindar recomendaciones $\mathrm{y}$ asesoramiento orientados hacia el lado contrario.

En este sentido, se advertía que en el caso de las sociedades post-conflicto, un Estado débil sin legitimidad puede colapsar o fallar, de modo que no está preparado para "organizar el ejercicio del poder", tendiendo a reducirse 
en beneficio directo de un grupo selecto de intereses, siendo inviable que ejerza el uso de la fuerza en un determinado territorio (Pearce, 1999:54). Es en este contexto que las elites procuran una modernización asociada principal y únicamente a la liberalización de la economía, desatendiendo (no sin intención) el compromiso para una democratización sustantiva, lo que incluye el descuido de la construcción de instituciones representativas y medidas redistributivas. En Guatemala, "Los grupos dominantes no fueron dañados por el conflicto (...) conservaron su talante de clase intacto y después de 1985 se habían distanciado de la elite militar (...) la elite estuvo por la paz pero en contra de los acuerdos (...) ahora disfrutan del mercado libre, del Estado mínimo, de la flexibilidad laboral, del control financiero" (Torres Rivas, 2006: 30). Esto no sorprende demasiado si recordamos la fuerza que adquirió el neoliberalismo en las décadas de 1980-90, pero sí llama la atención que se tienda a dejar de lado este contexto en el que se forjó la paz.

Precisamente, al estar el foco colocado en el mercado, poco importó que las IFIs, organismos internacionales, ONGs, fundaciones, fueran "reemplazando" paulatinamente al Estado, en particular en su rol social. No se discutió demasiado qué tipo de economía se debía promover para lograr una democracia con justicia social a mediano-largo plazo. ${ }^{13}$ Asimismo, la liberalización de la economía vino acompañada de la "necesidad" de reformas institucionales fundamentales para garantizar la estabilidad que requiere la economía de mercado (más que estar orientadas hacia un horizonte de justicia social). ${ }^{14}$

\section{LAS ONGS ESTADOUNIDENSES EN GUATEMALA Y LA RED GLOBAL DE PODER}

De un listado de 200 ONGs en Guatemala, ${ }^{15}$ al menos 55 son estadounidenses. Los sectores que abarcan estas ONGs son preferentemente: la educación y asistencia a niños y adultos, atención en salud, empoderamiento

\footnotetext{
13 Jonas advirtió sobre esto en el caso de los Acuerdos de Paz de Guatemala (2000: 206-217).

14 En este sentido, fue fundamental el proceso de reforma judicial, realizada en parte en el marco del asesoramiento proveniente del sector privado-público estadounidense. Un ejemplo de esto lo veremos a continuación, es la ong Partners for a Democratic Change, que trabajó en conjunto con la USAID para implementar reformas en el ámbito judicial guatemalteco.

15 Listado realizado por http://weguatemala.org/es/nonprofit_directory; por cierto también de origen estadounidense.
} 
de las mujeres, asesoramiento para el desarrollo de micro emprendimientos (artesanía principalmente) y producción agrícola.

A primera vista, cada página web de estas ONGs, presenta una foto de las personas a las que está beneficiando (o a las que "usted podría beneficiar con su donación"). Así, se ven de modo recurrente caras de niños indígenas sonriendo, campesinos trabajando a gusto y mujeres realizando tareas de artesanía y organización comunitaria con mucha alegría. La imagen es que con la asistencia, todo funciona mejor. ${ }^{16}$ Hay varias cuestiones para discutir sobre esta manera de abordar los problemas histórico-estructurales de países desiguales y dependientes.

Una de ellas, es que tal como se lleva a cabo la asistencia, se observa que es claramente parte de un "un mercado crecientemente competitivo y empresarial" (Unger, 2009: 23), donde los donantes invierten para mejorar la calidad de vida de otras personas. En este mercado hay desde donantes mega-millonarios hasta amas de casa y familias que ofrecen apenas unos dólares. ${ }^{17}$ Las personas famosas son un pilar fundamental de este mercado (estrellas de cine, deportistas, artistas, etc.). Incluso determinadas ONGs proponen que "Ud., al donar, también podrá convertirse en una celebridad" y figurar junto a famosos de Hollywood (por ejemplo, Children. org) ${ }^{18}$. También hay ongs que están en el "top ten" en cuanto a eficiencia de las inversiones y resultados en las comunidades en las que trabajan, es decir, la caridad es también materia de competencia y efectividad (Charity Navigator.org). ${ }^{19}$ La mayoría de estas organizaciones se mueven gracias a los ideales más nobles y los mejores deseos de las personas de clase media o adineradas de países centrales y periféricos que están dispuestas a dedicar algo de su tiempo/dinero (léase: una temporada, la vida post-jubilación, un período de "aventura"), a mejorar las vidas de otras personas "desafortunadas". Aparentemente, serían irreprochables estas actitudes y acciones de buena voluntad. Sin embargo, no dejan de estar inscritas en la lógica de la acción instrumental que caracteriza a las relaciones en el

\footnotetext{
16 Ver por ejemplo: http://www.globalfairness.org/; https://www.children.org/; http:// www.commonhope.org/; http://www.sharedbeat.org/

17 Aquí podemos tender un vínculo entre la asistencia y la moral católica y las prácticas "altruistas" filantrópicas, que si se indaga un poco, en lugar de plantear una lógica diferente a la capitalista, terminan por alimentarla (Ver: Picas Contreras, 2006, especialmente las alusiones a las reflexiones de Bourdieu con respecto a la caridad).

18 https://www.children.org/Celebrity-Supporters

19 http://www.charitynavigator.org/
} 
sistema capitalista, lejos de plantear otro tipo de dinámica (ver: González Butrón, 2010; Picas Contreras, 2006).

La caridad es parte de los negocios al menos desde principios de siglo $\mathrm{xx}$, y en el caso de Estados Unidos, se desarrolló especialmente en el seno de las familias millonarias como Rockefeller o Morgan. Uno de los objetivos más claros de la conformación de "Fundaciones" es el de no pagar impuestos. Esto lo analizó con mucha categoría Wright Mills (1978). Actualmente, el tema de la financiación es discutido incluso desde algunas ONGs estadounidenses, que señalan que la mayoría de las fundaciones surgieron como una estrategia de las corporaciones para no pagar impuestos y para que los descendientes pudieran recibir la herencia de los magnates sin pagar un peso al Estado (Smith, 2007: 5). De hecho, Kivel (2007: 118) apunta que al hacer esto, roban del erario público lo que debería llegar a la gente a la que luego ellos "ayudan" proporcionando un porcentaje de dinero mínimo con respecto a lo que debería haber fluido a esos sectores en caso de que se hubieran pagado los impuestos sin exenciones. De hecho, de las ONGs estadounidenses en Guatemala, vemos que la mayoría son corporaciones de caridad sin fines de lucro, inscritas en el 501(c)(3) de deducción impositiva por caridad en el marco de Servicio a los Impuestos Internos de Estados Unidos y registradas como organizaciones sin fines de lucro exentas de impuestos en la República de Guatemala ${ }^{20}$.

Otro aspecto fundamental del mercado de la asistencia es el modo en que tienden a operar emulando a las empresas transnacionales (Barnet y Muller, 1974; Petras y Veltmeyer, 2007). En este sentido, todos los ejecutivos, mesas directivas, coordinadores, etc. son estadounidenses profesionales (a esto pueden sumarse encargados locales), algo similar a la dinámica implementada por las empresas transnacionales especialmente luego de la Segunda Guerra Mundial: los que mandan están en el país de la casa matriz, pues son los que de hecho conocen sobre el tema; el "know how" de cómo organizar ese tipo de actividades, proyectos, etc., sigue estando en el que invierte. A nivel discursivo, el compromiso con una ong es presentado como una manera "cool" (buena onda) y "amorosa" de atender a los desvalidos (aunque en esencia -y a pesar de que los mismos voluntarios no se hayan informado al respecto- sea una herramienta para garantizar la reproducción de las relaciones centro-periferia). Los jóvenes que se unen a estos proyectos, saben

20 En 1998, había nada más y nada menos que 734.000 organizaciones en EEuU que se regían por esta ley. 
que ellos sí provienen de sociedades “civilizadas”, ellos sí son privilegiados y por eso tienen que enseñar a la gente a vivir de modo tal que se asemeje a dicho modelo. Esto refuerza las asimetrías, pues es poco probable (aunque seguramente habrá excepciones) que esta gente desarrolle una crítica profunda al modo en que sus propios gobiernos y empresas aportaron y contribuyen a la reproducción de estas condiciones de vida en la periferia en términos económicos, políticos, militares y culturales. ${ }^{21}$

Por último, prolifera la concepción de que las ongs son en general emprendimientos "aislados" de gente de buena voluntad que nada tiene que ver con las empresas transnacionales, organismos internacionales, instituciones financieras y Estados que han sido medulares para la reproducción del sistema capitalista (y por tanto, de las desigualdades que justificarán la asistencia). Lo real es que muchas ONGs "están sobre todo comprometidas con el sector privado y con los Estados, en vez de actuar como actores independientes o incluso como contrapoder" (Teil, 2010). De esta manera, las oNGs forman parte de la trama de la red de poder global (red invisible de poder) ${ }^{22}$ cumpliendo una función ideológica ${ }^{23}$ fundamental en cuanto a la supuesta "concreción" de los principios liberales de igualdad y fraternidad.

21 Consideramos que una excepción en Guatemala es el colectivo NISGUA, Network in Solidarity with the People of Guatemala: "Pues, la cosa es que como somos una organización estadounidense, esa es nuestra orientación, tenemos sede en California, y trabajamos aquí diferentes temas (...) Pero una de las razones por las que vemos como importante la presencia y ese trabajo solidario, es por la posición de nuestro propio gobierno en la revolución. Mejor dicho, las intervenciones estadounidenses (...). Entonces, eso de la revolución, la participación de nuestro gobierno en el golpe de Estado, todo eso, es algo muy fundamental en la educación que hacemos en Eevu. Porque como nuestro trabajo es más de base, más con gente común de nuestras comunidades en EeUU, sí hacemos cabildeo con los poderes en sí del gobierno de EEUU, pero principalmente hacemos ese tipo de educación popular con nuestras comunidades. Y esto se necesita como una orientación histórica porque muchos no saben de esa parte de nuestra relación con Latinoamérica y mucho menos con Guatemala" (Entrevista de la autora a integrante de Nisgua, Ciudad de Guatemala, marzo 2012). Ver también: http://nisgua.blogspot.com.ar/.

22 Este es el concepto utilizado por Wright Mills cuando se refiere a las conexiones que articulan a la elite del poder a nivel nacional y que puede extenderse a nivel internacional. Recomendamos también Rothkopf, 2008.

23 Retomando la idea gramsciana de hegemonía, la asistencia, en particular la proveniente del sector privado, puede ser considerada como una parte esencial en la promoción de un consenso a favor de la democracia capitalista (Roelofs, 2007: 480). Así, la "filantropía" que es funcional para la reproducción de las desigualdades y con ello, la perpetuación de las élites en el lugar privilegiado, puede ser asumida (no siempre lo es) por las clases medias y populares como una acción positiva e incluso necesaria. 
En Guatemala, operan entre otras, las siguientes ONGs dedicadas a determinados rubros: Let me Shine, enseñanza de niños; Mil Milagros enseñanza de niños; ALAs, planificación familiar; Shearing the Dream, proyectos de artesanía, atención a ancianos, becas para alumnos de primaria, atención médica en la selva, hostel para voluntarios, fair trade; Global Fairness Org., trabajo decente, micro-inversiones, innovaciones financieras, mejoras en el acceso al mercado; Children.org, financia a niños de modo individual, educación, apoyo familiar, ayuda en caso de desastres naturales; Shared Beat, asistencia a niños; De la gente, producción-venta de café, intercambio cultural y turismo; Mayan Families, asistencia para niños, madres, ancianos, asistencia en educación; Wuqu qawok, salud, agua potable, proyectos de idiomas; Soluciones Apropiadas, empoderamiento de mujeres, comercialización de cocinas; Inside Org, asesora a las ONG a nivel global, genera vínculos entre ONGs, proporciona cursos de capacitación; Common Hope, educación, salud y construcción de vivienda; Child Aid, campañas de alfabetización; Safe Passage, educación de niños y adultos, atención de salud, emprendimientos sociales; Semilla Nueva, agricultura sustentable; Rising Minds, construcción sustentable, jardinería y nutrición, educación y enriquecimiento cultural, educación en salubridad, inmersión cultural, turismo; As Green As it Gets, producción de café, artesanías, tecnologías apropiadas, proyectos comunitarios, préstamos, sustentabilidad ambiental; Mayan Hands, artesanías hechas por mujeres mayas que se venden en los EeuU; Helps International, busca crear bienestar y estabilidad en las zonas rurales y promueve la producción de maíz; Acción Guatemala, red para financiar proyectos sobre comunicación, medioambiente, cultura, comunidad, arte, música y salud; Service for Peace, voluntariado de asistencia para niños; Fundación Todos Juntos, apoyo familiar, educación, formación para la -adecuada- utilización de cocinas; Social Entrepreneurs, promoción y organización de la microfinanza (sistema promovido por las TED Conferences), mejorar la inserción en el mercado; Starfish, asistencia a mujeres, jóvenes y educación para el liderazgo; Aviesca, reciclado, pequeña librería, laboratorio de computación, turismo; Miracles in Action; educación y nutrición; Cooperative for Education, cooperativa de educación; Cultural Survival, protección de derechos indígenas, programa de radio, artesanías, rescate de lenguas en extinción; Education for the Children, educación para niños y adultos, asistencia en alimentos y salud. 
El listado obedece a las ONGs estadounidenses en Guatemala, país donde además, hay una importante cantidad de ONGs provenientes de Europa y Canada. En esta ocasión abordamos lo relativo a organismos con base en Estados Unidos debido a: aspectos cuantitativos y cualitativos (constituyen una buena cantidad y abarcan campos de acción muy diversos); los procesos históricos que asocian a ese país con Guatemala y por la presencia del gobierno estadounidense en programas y planes para la seguridad y el "desarrollo" de Guatemala, hoy especialmente visible en el apoyo a la Alianza para la Prosperidad y la Iniciativa para la Seguridad de Centroamérica (CARSI); varias de las ONGs estadounidenses están asociadas a una red de poder que tiene importante incidencia en América Latina.

Tomaremos algunos ejemplos que dan cuenta de la red global de poder -que no intentan ser exhaustivos, sino que pretenden esbozar un esquema de cómo se insertan estas ONGs en la red de poder. El primero es el de Global Fairness Initiative, ${ }^{24}$ cuyo slogan es "soluciones locales para una economía global". Esta ONG dedicada a promover mejores condiciones de trabajo, pequeñas inversiones y emprendimientos para el acceso al mercado por parte de gente en situación de pobreza, es financiada por empresas como Chevron Corporation y Pfizer, ${ }^{25}$ por fundaciones como Open Society, la Fundación de la familia Clinton, el Consejo para Relaciones Exteriores, la Corporación Financiera Internacional, Partners for a Democratic Change y el Departamento de Estado de los Estados Unidos.

Si revisamos cada una de estas empresas y corporaciones, veremos que la Open Society es una fundación de Soros, uno de los mega-especuladores a nivel mundial, que ha llevado a la quiebra a Estados enteros, pero que ahora puede mostrar "el rostro humano" del capitalismo a través de la asistencia. Por su parte, la Corporación Financiera Internacional (CFI) forma parte del Grupo Banco Mundial. Curiosamente, como hemos referido más arriba, es uno de los organismos que tiene presencia en Guatemala desde 1956 (pleno gobierno contrarrevolucionario y represor de Castillo Armas). En la actualidad, la CFI provee acceso a financiamiento para pequeñas y medianas empresas, también invierte en proyectos de infraestructura y energía. En el 2012 invirtió 120 millones de dólares en torres de celulares

\footnotetext{
24 http://www.globalfairness.org/

25 Farmacéutica que fue acusada de testear sus productos con gente en Nigeria. Tal vez este sea el ejemplo más crudo de etnocentrismo y de reproducción de las relaciones centro-periferia ancladas en el racismo y el desprecio por la "otredad". Ver: http://www.worldpress.org/africa/1190.cfm
} 
y también aportó a un proyecto para la homogeneización de la logística en América Central y de la banca móvil, así como la compra de activos de la compañía de seguros guatemalteca G\&T (Central America Data, 2012). Es bastante claro cuál es la idea de "desarrollo" de este organismo, vinculada a la financiarización de la economía y totalmente centrada en el rubro de servicios (¿en qué medida estos proyectos mejoran la calidad de vida de niños de 0 a 5 años con desnutrición?). ${ }^{26}$

Otro de los organismos vinculados a CFI es Partners for a Democratic Change (PDC), que, surgido en 1989, se ocupa de asesorar a los gobiernos en la resolución de conflictos, construcción de consenso, y cuestiones jurídicas, en síntesis: asesora a gobiernos "en transición” para lograr "gobernabilidad”. De hecho, PDc está en Guatemala desde 2010 trabajando en conjunto con Tetra Tech Company (de California) asesorando al gobierno nacional para lograr una administración sustentable y eficiente. Esta tarea se desarrolla en el marco del proyecto de la Agencia Internacional para el Desarrollo de los Estados Unidos (USAID) titulado "Project against violence and impunity". Vale recordar aquí el objetivo de unos estándares de legalidad "mínimos" para el buen desarrollo de los negocios, tal como lo propone la Alianza para la Prosperidad. Por otra parte, ya hemos descrito mínimamente el rol de la USAID en el marco de la Alianza para el Progreso en los '60 (asistencia para el desarrollo + contrainsurgencia). En la actualidad, la USAID ha sido acusada de estar vinculada a procesos de desestabilización en Venezuela, Bolivia y Honduras (Allard y Gollinger, 2008). De hecho, el presidente de Bolivia Evo Morales expulsó a dicho organismo del país por injerencia en asuntos nacionales. ${ }^{27}$

\footnotetext{
26 Bill Clinton nos proporciona la respuesta, al menos en lo relativo a la vinculación celulares-desarrollo: "Es difícil calificar de organizado a cualquier mercado de telefonía celular, pero su expansión en los países pobres tuvo un impacto muy positivo en las economías locales. El emprendedor Mo Ibrahim, nacido en Sudan, hizo fortuna apostando a la telefonía celular en África. En el 2005, el 11\% de la población tenía acceso a celulares y su número creció rápidamente. El hombre de negocios irlandés, Denis O’Brien es el mayor operador de telefonía celular de Haití. Los jóvenes ahora trabajan vendiendo tarjetas de celular en las calles, lo que significa que se creó un nuevo tipo de empleo para personas que estaban desesperadas por trabajar" (2008:172). Queda bastante clara la noción de desarrollo, que se atiene más bien al crecimiento del mercado de consumidores.

27 En el mes de agosto de 2015 se profundizó la polémica entre el gobierno de Bolivia y las ONGs, en el marco de una severa crítica que la gestión de Morales ha lanzado contra la conducta y la finalidad de la asistencia para el desarrollo en ese país. Con respecto a las ONGs, numerosos intelectuales defienden su accionar, ver: http://www.eldeber.com.
} 
Otro organismo asociado a Global Fairness Org. es la Fundación de la Familia Clinton, que se dedica a promover la "colaboración creativa de pequeños emprendimientos, ONGs, gobiernos y gente". En este sentido, es esclarecedor el libro escrito por el propio Bill Clinton sobre la caridad, en el que asegura que todos podemos aportar para combatir la pobreza, sea con un par de centavos o con millones de dólares (Clinton, 2008). Su mujer, ex secretaria de Estado del gobierno de Obama y actual candidata a la presidencia por el partido demócrata, alguna vez sintetizó el eje de la cuestión: lo que busca la asistencia es lograr que la gente se posicione del "lado correcto del capitalismo" (Rodham Clinton, 2010). La noción de desarrollo impulsada desde esta perspectiva es generar, cueste lo que cueste, caiga quien caiga, consumidores o potenciales consumidores, de modo que la asistencia es concebida como una herramienta que permite salir de la pobreza para ingresar al mercado, para generar consumidores pues finalmente, desde el paradigma neoliberal, esa acción es la que los constituye como sujetos (González Butrón, 2010). Por eso, la familia Clinton recibe con entusiasmo el financiamiento de la Fundación Bill \& Melinda Gates, que tienen una visión similar: la salud y la educación también son un negocio lucrativo, y lo importante es que lo que sobra en el mundo son pobres que necesitan que alguien coordine y alimente el mercado de la asistencia (pues como apuntábamos, son cada vez menos los Estados que pueden atender estas necesidades) (Delgado y Romano, 2013).

Dos ejemplos más que valen la pena. Uno es el de INside.org ${ }^{28}{ }^{28}$ que es el paradigma de la asistencia como mercado y como un nuevo espacio de reproducción de burocracias y profesionalización de las ONGs (aunque con un aspecto más "juvenil" y tecnológico) pues es un organismo que se encarga de asesorar a otras ONGs a nivel mundial (y como tal, también opera en Guatemala). Entre sus "partners" encontramos a Citibank, Hoteles Barceló, la Fundación Shell, Pathfinder Co., y a la Fundación Bill \& Melinda Gates, a los Partners for a Democratic Change, Hope y la Pan American Development Foundation.

Sobre estas empresas transnacionales que financian a esta ONG con "buenas intenciones y ganas de cambiar el mundo", son harto conocidas las estrategias de transferencia de excedentes practicadas en la periferia: extracción

bo/bolivia/intelectuales-piden-garcia-linera-respete.html. Con respecto a la postura del gobierno ver: http://rebelion.org/noticia.php?id=202285.

28 https://insidengo.org/ 
de recursos naturales, hiper-explotación de la fuerza de trabajo, acaparamiento del mercado interno, dumping, creación de plataformas de exportación, desarticulación de la industria local, no transferencia de konw how, etc. (Ver: Baran y Sweezy, 1974; Petras y Veltmeyer, 2007; Romano, 2013). La relación de INSIDE.org con estas empresas, debería generar al menos "dudas" sobre quiénes se benefician con las donaciones y los proyectos de asistencia.

Con respecto a las otras fundaciones, vemos que vuelven a aparecer las mismas que financian a otras ONGs, lo que muestra una creciente burocratización del "tercer sector", repitiendo hasta cierto punto la dinámica de los Estados (por cierto, criticada por estas mismas ONGs). Por otra parte, en el caso de Guatemala observamos que de modo directo o indirecto, estas ONGs se articulan con organismos del gobierno estadounidense, ${ }^{29}$ lo que nos lleva a cuestionar si esta "oenegeización" no puede considerarse como otra estrategia para lograr metas ya conocidas: imponer políticas y lineamientos que beneficien a la elite local articulada al sector privado-gobierno de Estados Unidos y demás países centrales, aceitando el modo en que opera el capital en la periferia en general.

Siguiendo con nuestro argumento, vemos que INSIDE.org tiene cerca de 500 "partners". Uno de ellos es la Pan American Development Foundation (PADF). Este organismo fue creado en 1962 con el apoyo de la oza y el financiamiento de USAID, el BID y el Social Progress Trust Fund (es decir, todas instituciones asociadas al gobierno estadounidense y a las IFIs). Lo más interesante es que la PADF se crea gracias a la motivación brindada por una experiencia de caridad llevada a cabo por un estadounidense en Guatemala, a finales de los '50, para dar pequeños préstamos a los indígenas que no tenían acceso al crédito "The penny foundation" (que todavía sigue vigente). En la actualidad, la PADF se ocupa de movilizar al sector privado, impulsando pequeños emprendimientos y asesoramiento técnico. Algunas de las empresas que los auspician son Caterpillar y Pfizer, y actualmente están promoviendo un proyecto de educación para evitar la deserción escolar de niños en Guatemala, con el apoyo de las transnacionales Telefónica y Cinépolis. Por último, pero no menos importante, muchas de las actividades pautadas por INISDE.org son organizadas con la USAID y para la USAID, como las siguientes: "USAID Rules \& Regulations: Grants \& Cooperative Agreements" workshop in Cape Town, South Africa

29 Un caso paradigmático es el de Haití, donde entre agencias del gobierno estadounidense como la USAID y agencias de otros gobiernos de países centrales, financian el $70 \%$ de las ONGs (Edmonds, 2013:5). 
(June 29 2015); USAID Contract Management for NGOS - An Introduction workshop in Washington, DC (June 29 2015); Procurement Planning \& Execution: USAID Grants \& Cooperative Agreements workshop in Accra, Ghana (July 9 2015). Así se genera toda una burocracia de cómo asesorar a ONGs para que participen del financiamiento de organismos estatales.

Otro caso es el de la ONG "Semilla Nueva", ${ }^{30}$ dedicada a "agricultura sustentable", que se encuentra directamente articulada con el cGIAR (Grupo Consultivo para la Investigación Agrícola Internacional) y el сммүт (Centro Internacional de Mejoramiento del Maíz y el Trigo). Estas dos entidades, encuentran su raíz en la Revolución Verde, formando parte del complejo agro-industrial que monopoliza los agroquímicos y semillas mejoradas, que poco tienen de "sustentables" para el ambiente, y que en cambio han sido exitosas en la expansión de agro-negocios millonarios (Delgado y Romano, 2013: 16).

A esta dinámica hay que sumar las ONGs guatemaltecas, que reproducen esta lógica y que forman parte de la reconstrucción del Estado creado a partir de los Acuerdos de Paz. Lo curioso es que una de las escasas publicaciones que analiza críticamente a las ONGs guatemaltecas y que ha adquirido mayor difusión en la red, ha sido realizada por dos periodistas extranjeros (Rico y Grange, 2004), que evita mencionar la red global de poder en la que se inserta la lógica de las ONGs y su argumento lleva a concluir que el problema es que en Guatemala y en América Latina hay una especial inclinación a la corrupción. Para ello toma como confiables los datos provistos por la embajada estadounidense y la Fundación Soros. Considerando que es fundamental conocer el modo en que la elite política y económica local opera en detrimento de las mayorías (utilizando los aparatos del Estado), alertamos sobre las críticas que se hacen desde los países centrales a la corrupción en la periferia, que desconocen o minimizan el rol de sus propios gobiernos y empresas en esta dinámica, advertencia planteada seriamente ya por el canadiense Edmonds (2012) en su artículo sobre las ONGs en Haití (sin duda un caso paradigmático con respecto a la asistencia).

\section{LA MILITARIZACIÓN: EL ESTADO NO FALLIDO}

Al menos desde finales de la Segunda Guerra Mundial, la asistencia para el desarrollo está vinculada a la asistencia militar, pues son dos procesos de una misma estrategia de estabilización a favor del flujo del capital privado

30 http://semillanueva.org/ 
y público, ${ }^{31}$ operando (una de modo indirecto, la otra de modo directo) para truncar y desarticular procesos orientados a reformas y cambios estructurales. Luego de los Acuerdos de Paz en Guatemala, al no cumplirse las promesas de bienestar económico y social, los índices de violencia se incrementaron, sumado a la creciente presencia del narcotráfico, a la vez que, a pesar de la claridad de los acuerdos respecto a la necesidad de subordinar a las FFAA al poder civil, en resumen, los resultados han sido escuetos.

Por un lado, es claro que la transición llevó a que buena parte de la policía y FFAA contrainsurgente, pasara a formar las filas de las "nuevas fuerzas de seguridad", con lo que ello implica (Kruijt, 2011). ${ }^{32}$ Por otro lado, es difícil que las FfaA pierdan su rol primordial de garantes del orden en un contexto de exacerbación del crimen organizado como nuevo enemigo interno. A diferencia de lo que suele pensarse, esto no es reciente (aunque se ha exacerbado sin dudas en los últimos años). Como apuntaba Jonas (2000: 243): “Todavía no se había secado la tinta de los acuerdos que liberaban al ejército de cualquier otra función que no fuera la seguridad externa, y ya los funcionarios estadounidenses sostenían conversaciones con el presidente Arzú, en ese mismo momento y lugar, proponiendo darle al ejército guatemalteco una 'nueva misión' en operaciones antinarcóticos" ${ }^{33}$

Debemos considerar en este sentido, que Guatemala es parte de un espacio geopolítico y geoeconómico crucial (Centroamérica y el Caribe) no sólo para Estados Unidos, sino también para otras potencias como China. Y aquí cumple un rol primordial el gobierno estadounidense, que se materializa no solo en los sucesivos y constantes acuerdos de seguridad, sino en los acuerdos comerciales como la mencionada Alianza para la Prosperidad. Si bien en los últimos años el presupuesto de asistencia militar del país del Norte hacia América Latina ha tendido a descender en virtud de lo destinado a la "asistencia para el desarrollo", la asistencia militar estadounidense para los países de Centroamérica no sólo no disminuyó sino que en 2013 se incrementó en un 35\% (Poe, 2012: 3).

\footnotetext{
31 Un ejemplo concreto de esto es la Ley de Seguridad Mutua de 1951 que suponía acuerdos bilaterales con otros países, centrados en ayuda militar, ayuda económica y asistencia técnica (Morley en Guess, 1987: 33).

32 Con respecto a esta temática, ver varios capítulos en Donadío (2010).

33 Para profundizar sobre el rol de las FFAA en el Estado y gobiernos guatemaltecos ver: Schirmer, 1998.
} 
Tabla ${ }^{\circ} 1$. Venta de armas de Estados Unidos a América Latina (por país, en dólares)

\begin{tabular}{lccccc}
\hline País & 2008 & 2009 & 2010 & 2011 & 2012 \\
\hline Colombia & $419,145,722$ & $240,651,99$ & $538,137,238$ & $287,501,238$ & $304,329,724$ \\
El Salvador & $16,217,575$ & $15,863,813$ & $8,214,579$ & $11,480,151$ & $11,878,202$ \\
Belice & 777,878 & 602,075 & $1,383,296$ & $2,206,510$ & $3,343,957$ \\
Guatemala & $7,910,285$ & $28,635,156$ & $5,390,671$ & $6,432,741$ & $21,510,458$ \\
Honduras & $9,597,745$ & $5,002,600$ & 768,843 & $1,391,291,958$ & $53,734,218$ \\
México & $749,985,108$ & $974,901,419$ & $475,061,022$ & $377,114,824$ & $1,218,829,057$ \\
Perú & $50,130,166$ & $26,718,768$ & $30,891,163$ & $409,392,833$ & $27,545,252$ \\
\hline
\end{tabular}

Fuente: Security Assistance Monitor, 2014

Esta asistencia se materializa a su vez en la presencia de tropas estadounidenses en la región. Para brindar un dato ilustrativo, a fines de mayo de 2015 se hizo público el despliegue de tropas en Centroamérica (liderado por el Comando Sur), protagonizado por 280 marines que se ocuparán del entrenamiento de fuerzas locales para combatir al crimen organizado y realizar tareas de rescate ante desastres naturales (Romano, 2015). Sin embargo, el General Kelly, a cargo del Comando Sur, según su alocución al Congreso estadounidense de marzo de 2015, asegura que la asistencia militar a los países del Triángulo Norte es insuficiente, y que entonces, otras naciones de Centroamérica podrían aprovechar ese vacío, naciones que no observen como parte de la asistencia en seguridad a la promoción de los $\mathrm{DDHH}$, las medidas en contra de la corrupción y la protección del medio ambiente, como sí lo hace Estados Unidos (Kelly, 2015: 15). A pesar de estas debilidades, Kelly asegura que la DEA (organismo nacional estadounidense que actúa en Centroamérica con pocas o ninguna restricción) ha contribuido a mejorar la seguridad de la región, y que en el caso de Guatemala, otorgó apoyo en infraestructura e invirtió 17 millones de dólares en equipos y entrenamiento para las fuerzas inter-agencia que operan en las fronteras sur y norte (Ibid, 17).

Más allá de las posturas e intereses de cada sector, interesa reflexionar sobre el rol de las FFAA en Guatemala, que aún no se circunscribe a lo pautado en los Acuerdos de Paz. En cambio, se percibe una "securitización" (más allá del discurso de la guerra contra el narco-terrorismo) en el modo de enfrentar la "cuestión social": las múltiples demandas por acceso/derecho a la tierra, educación, sanidad, salud, etc. en buena medida impulsadas 
por las comunidades indígenas y campesinas, han tendido a ser "resueltas" a través de la represión militar y policial (Ver: UDEFEGUA-El Observador, 2010; Romano, 2012a). En el año 2014 se registraron 766 agresiones contra defensoras y defensores de DDHH en situaciones especialmente vinculadas a defensa del medio ambiente ante megaproyectos, incluidos la intimidación, la persecución, los daños a la propiedad, ejecuciones extrajudiciales, etc. (Udefegua, 2014).

\section{REFLEXIONES FINALES}

Luego de la Segunda Guerra Mundial se consolidó y logró una mayor institucionalización la asistencia "para el desarrollo" como uno de los pilares de las relaciones centro-periferia, impulsada desde los organismos internacionales y los gobiernos centrales como un modo de achicar la brecha con los países "subdesarrollados". Sin embargo, el modo en que se llevó a cabo esta asistencia y los intereses que subyacen a ella, tienden a alimentar la dinámica desigual no solo en lo económico, sino en cuanto a lo político e institucional. De este modo, el rol del Estado en la redistribución generó conflictos claros en el contexto de Guerra Fría, dirimiéndose a favor de un mayor protagonismo del mercado (materializado en las políticas neoliberales). En el caso de Guatemala, el rol del Estado es más controversial aún porque desde el derrocamiento de Arbenz se perfiló como organización contrainsurgente, más que como garante de los derechos (civiles, sociales, económicos, políticos) de los guatemaltecos.

Pasadas ya varias décadas desde los Acuerdos de Paz, se observa que al no haberse logrado avances importantes en términos económicos y sociales a favor de las mayorías, se complica cada vez más acceder a la tan ansiada institucionalización y organización del Estado en pos del bien público. En su lugar, el Estado ha operado sistemáticamente a favor de las elites políticas y económicas que van renovando sus discursos y prácticas para mantener su lugar de privilegio, haciendo determinadas concesiones para que Guatemala se inserte en el mercado internacional. En este contexto, llama la atención que algunas ONGs, fundaciones e instituciones filantrópicas en apariencia no vinculadas a ningún Estado o gobierno, operen en los hechos a favor de la reproducción del sistema desigual y contribuyen a consolidar la dependencia del país respecto del financiamiento extranjero, y con él, del asesoramiento y "know-how" del sector privado, empresas transnacionales y organismos internacionales. No se trata de reivindicar aquí un discurso 
nacionalista anquilosado, sino de contribuir a la discusión sobre quiénes están tomando las decisiones y actuando, a favor de qué sectores y grupos (locales, nacionales y transnacionales). Asimismo, intentamos aportar a la discusión sobre qué se define como "desarrollo", para qué y para quiénes, buscando ir más allá de la retórica de los organismos internacionales, los mandatos del mercado y las supuestas vías alternativas, asunto que es un enorme desafío en el contexto de una red de poder global cada vez más sólida y menos visible.

Ante esta dinámica del capital, es imperioso señalar que las comunidades campesinas e indígenas se han mantenido en pie de lucha para reivindicar sus derechos, especialmente aquellos acordados en los Acuerdos de 1996. Por otra parte, recientemente la clase media urbana ha tomado las calles de la ciudad capital para pronunciarse contra la corrupción y la impunidad. Así, con su enorme diversidad, las divergencias y clivajes (además de las heridas todavía abiertas por el terrorismo de Estado) la gente está saliendo de décadas de silencio y aparente apatía.

Interesa destacar que lo que tendió a articular las diversas protestas en el 2015 ha sido la lucha contra la corrupción, asociada al rechazo por "la política y los políticos". Por un lado, esto redituó en un éxito incipiente pues se logró la renuncia de la vicepresidenta Roxana Baldetti y del presidente Otto Pérez Molina que se encuentran detenidos por su presunta participación en una red de negocios ilegales. Por otro lado, también llevó a ganar las elecciones presidenciales (septiembre-octubre 2015) a un candidato que se presentó como "anti-político", Jimmy Morales, pero que en los hechos está fuertemente vinculado a la derecha guatemalteca.

El resultado electoral, más allá de lecturas superficiales, muestra una continuidad con la vieja política en términos de democracia de fachada, pues desde el nuevo gobierno no se apunta a ningún tipo de cambio estructural. Nos obliga entonces a seguir pensando y debatiendo sobre el rol del Estado y su vínculo con el financiamiento externo y el desarrollo del "tercer sector" de cara a la Alianza para la Prosperidad y el CARsi. En síntesis, invita a reflexionar sobre la sustancia y el contenido de la democracia en Guatemala en un contexto de dependencia económica y política que por momentos parece profundizarse. 


\section{BIBLIOGRAFÍA}

ALLARD, G. y E. Gollinger (2009); USAID, NED y CIA. La agresión permanente. Caracas: Ministerio del Poder Popular para la Comunicación y la Información.

BARAN, P. y P. Sweezy (1974); El capital monopolista. Ensayo sobre el orden económico y social de los Estados Unidos. Buenos Aires: Siglo XXI.

BANCO MUNDIAL (2015); “Guatemala Panorama General”. http://www.bancomundial.org/es/country/guatemala/overview

BARNET, R. (1974); Guerra perpetua. Los hombres y las instituciones detrás de la política exterior estadounidense. México: FCE.

BARNET, R. y R. Müller (1974); Poder Global: a força incontrolável das multinacionais. Río de Janeiro: Record

BANCO INTERAMERICANO de DESARROLLO (BID); Plan of the Alliance for Prosperity in the Northern Triangle: a Road Map. Regional plan prepared by El Salvador, Guatemala and Honduras. http://idbdocs.iadb.org/wsdocs/ getdocument.aspx?docnum=39224313 (septiembre de 2014).

BARREDA, C. (2007); "Guatemala: crecimiento económico, pobreza y redistribución”. http://www.albedrio.org/htm/documentos/CarlosBarreda-001.pdf.

BLÖMSTRON, M. y B. Hettne, B. (1990); La teoría del desarrollo en transición. México: FCE.

BLUM, L. (2001); "International NGos and the Guatemalan Peace Accords", en Voluntas: International Journal of Voluntary and Nonprofit Organizations, 12, 4 (December), pp. 327-353.

CAPUTO, O. y R. Pizarro (1975); Imperialismo, dependencia y relaciones económicas internacionales. Buenos Aires: Amorrortu.

CARDOZA y ARAGÓN, L. (1955); La revolución guatemalteca. México: Cuadernos Americanos

CENTRAL AMERICA DATA (2012); "Corporación Financiera Internacional en Guatemala", varios Artículos. www.centralamericadata.com/es/search?q1=content_es_le:\%22Corporaci\%C3\%B3n+Financiera+Internacional\%22\&q2=mattersInCountry_es_le:\%22Guatemala $\% 22$

, (2011); “Sector servicios lidera IED en Guatemala". http://centralamericadata.biz/es/article/home/Servicios_lidera_IED_en_Guatemala (2011a); “Inversión Extranjera Directa y Desarrollo". http://centralamericadata.biz/es/article/home/Inversion_Extranjera_Directa_y_Desarrollo

CLINTON, W. (2008); Doar. Como cada um de nós pode mudar o mundo. Río de Janeiro: Agir 
Congreso de Estados Unidos, Subcomité sobre América Latina, Comité sobre la Agresión Comunista de la Cámara Baja, septiembre octubre 1954.

COTLER, J. y R. Fagen, comp. (1973); Relaciones políticas entre América Latina y Estados Unidos. Buenos Aires: Amorrortu.

CULLATHER, N. (2002); PBSUCCESS. La operación encubierta de la CIA en Guatemala, 1952-1954. Serie de Autores Invitados, núm. 6. Guatemala: AvANCso

CHOMSKY, N. (2006); Failed States. The abuse of power and the assaul on democracy. New York: Metropolitan Books.

DELGADO RAMOS, G. y S. Romano (2010); “Economía política de la seguridad interna en América Latina: transferencia de excedentes, 'narco-insurgencia' y control social”, en Espacio Crítico, 13 (Julio-Diciembre), pp. 28-45. http://www.espaciocritico.com/sites/all/files/revista/recrt13/n13_a02.pdf

, (2013); Medio ambiente, fundaciones privadas y asistencia para el desarrollo en América Latina. México: CEIICH, unAm.

DONADÍO, M., comp. (2009); La reconstrucción de la seguridad nacional: defensa, democracia y la cuestión militar en América Latina. Buenos Aires: Prometeo.

DOS SANTOS, T. (1972); Socialismo o fascismo. El nuevo carácter de la dependencia y el dilema latinoamericano. Buenos Aires: Ediciones Periferia.

, (1975); "La estructura de la dependencia", en Economía política del imperialismo. Buenos Aires: Ediciones Periferia, pp. 41-64.

DREIER, J. (1962); La Alianza para el Progreso. Problemas y perspectivas. México: Novaro.

EDMONDS, K. (2012); "Beyond good intentions: The structural limitations of NGOs in Haiti", en Critical Sociology (April), pp 1-14.

FIGUEROA IBARRA, C. (1996); "Violencia política e insurgencia armada en Guatemala 1954-1995”, en C. Figueroa Ibarra (comp.), América Latina. Violencia y miseria en el crepúsculo del siglo. Puebla: BUAP-ALAs.

FOREIGN RELATIONS OF THE UNITED STATES (FRUS), 1961-1963, vol. XII, doc. 90, Report and recommendations of the Washington Assessment team on the Internal Security Situation in South America. United States Department of State, Office of the Historian, Kennedy Administration.

GERSON, A. (2001); "Peace Building: The Private Sector's Role”, en The American Journal of International Law, 95, 1 (January), pp. 102-119.

GLEIJESES, P. (1991); Shattered hope. The Guatemalan revolution and the United States 1944-1954. Estados Unidos: Princeton University Press.

GONZÁLEZ BUTRÓN, M. (2010); Ética de la economía. Reflexiones y propuestas de otra economía desde América Latina. México: Universidad Michoacana de San Nicolás de Hidalgo-Facultad de Economía / CIALC-UnAm.

GONZÁLEZ CASANOVA, P. (1979). Imperialismo y liberación. Una introducción a la historia contemporánea de América Latina. México: Siglo XXI. 
GUERRA BORGES, A. (2011); Guatemala: 60 años de historia económica Guatemala: Serviprensa.

GUESS, G. (1987); Development. Londres: Routledge library editions.

GUIMARAES, S. (2004); Cinco Siglos de Periferia. Una contribución al estudio de la política internacional. Buenos Aires: Prometeo.

HANDY, J. (1999); “Comunidad y revolución”, en G. Pelaez Almengor (comp.), Guatemala 1944-1954: los rostros de un país. Guatemala: UsAC / Centro de Estudios Urbanos y Regionales / Universidad de Tromso.

INSITUTO NACIONAL DE ESTADÍSITICA (INE) (2006); Encuesta general de condiciones de vida. http://www.ine.gob.gt/index.php/demografia-y-poblacion/42- demografiaypoblacion/64-encovi2006

JONAS, S. (1974); “'Showcase' for counterrevolution”, en S. Jonas y D. Tobis, And so victory is born even in the bitterest hours, North American Congress on Latin America (NACLA).

, (1979); "La democracia que sucumbió. La revolución guatemalteca de 1944 a 1954", en D. Tobis y S. Jonas, Guatemala, una historia inmediata. México: Siglo XXI, pp. 83-110.

JONAS, S. (2000); De centauros y palomas: El proceso de paz guatemalteco. Guatemala: FLACSO.

JOSEPH, G. (2004); "Lo que sabemos y lo que deberíamos saber: la nueva relevancia de América Latina en los estudios sobre la Guerra Fría”, en D. Spenser (coord.), Espejos de la Guerra Fría: México, América Central y el Caribe. México: Ciesas / Porrúa, pp. 67-94.

KELLY, J. (United States Marine Corps Commander, United States Southern Command), Before the $114^{\text {th }}$ Congress Senate Armed Services Committee, 12. http://www.southcom.mil/newsroom/Documents/SOUTHCOM_ POSTURE_STATEMENT_FINAL_2015.pdf (March 2015).

KIVEL, P. (2007); “Social service or social change?", en INSITE! The revolution will not be funded. Cambridge: INSITE! Women of color against violence-South End Press

KRUIJT, D. (2011); Drogas, democracia y seguridad. El impacto del crimen organizado en el sistema político en América Latina. Países Bajos: NIMD.

MATTELART, A. y Mattelart, M. (1997); Historia de las teorías de la comunicación. Barcelona: Paidós.

MÓBIL, J. (2010); La década revolucionaria 1944-1954. Guatemala: Serviprensa (Colección Cuadernos de Octubre).

PÁEZ MONTAlbÁN, R. (1998); La Paz Posible. Democracia y negociación en Centroamérica (1979-1990). México: Instituto Panamericano de Geografía e Historia; Centro Coordinador y Difusor de Estudios Latinoamericanos, UNAM. 
PEARCE, J. (1999); "Peace-Building in the Periphery: Lessons from Central America" Third World Quarterly, 20, 1 (February), pp. 51-68.

PETRAS, J. (1999); “Ngos: in the service of imperialism”, en Journal of Contemporary Asia, 29, 4, pp. 429-440.

PETRAS, J. y H. Veltmeyer (2007); Juicio a las multinacionales. Inversión extranjera e imperialismo. México: Lumen.

PICAS CONTRERAS, J. (2006); "Los límites de la solidaridad. Las ong y el mercado de 'bienes simbólicos' ”, en Gazeta de Antropología, 22, art. 8. España: Universidad de Granada.

POE, A. (2013); “The 2013 State Department and Foreign Operations Aid Request and Latin America and the Caribbean". Fact Sheet. Center for International Policy. Washington, D. C.

PREBISCH, R. (1949); El desarrollo económico de América Latina y algunos de sus principales Problemas. Santiago de Chile: CEPAL.

RICO, M. y B. Grange (2004); “El poder paralelo de las ong en Guatemala”, en Real Instituto Elcano de Estudios Estratégicos Internacionales, ARI 71.

RODHAM CLINTON, H. (2010); "Remarks on development in the 21st century". Washington, DC: Remarks to the Center for Global Development. www. state.gov/secretary/rm/2010/01/134838.htm.

ROELOFS, J. (2007); “Foundations and collaboration”, en Critical Sociology, 33 : pp. 479-504.

ROMANO, S. (2012); “La asistencia 'para el desarrollo' en las relaciones de Estados Unidos y América Latina”, en Análisis Político, 76, (Septiembre-Diciembre), Instituto de Estudios Políticos y Relaciones Internacionales, Universidad Nacional de Colombia, pp. 197-218.

(2012a); "Entre la militarización y la democracia: la historia en el presente de Guatemala", en Revista Latinoamérica, 55, Centro de Investigaciones sobre América Latina y el Caribe (CIALC) UnAM, México, 2012, pp 215-244. ISSN: 1665-8574.

, (2012b); “Los Wikileaks 'olvidados': documentos desclasificados del Departamento de Estado y el Derrocamiento de gobiernos latinoamericanos", en Revista Ibeorforum, año VII, 3, (Enero-Junio), México: Universidad Iberoamericana, pp. 128-172.

, (2013); ¿América para los americanos? Integración regional, dependencia y militarización. La Habana: RuthCasa Editorial.

, (2015); “Estados Unidos en América Latina: El huracán que no cesa”, en CELAG, Ecuador. http://www.celag.org/estados-unidos-en-america-latina-elhuracan-que-no-cesa-por-silvina-romano/ (3 de junio de 2015).

ROSTOW, W. (1961); Las etapas del desarrollo económico. Un manifiesto no comunista. México: FCE. 
ROTHKOPF, D. (2008); Superclasse. A elite que influencia a vida de milhoes de pessoas aorededor do mundo. Río de Janeiro: Agir.

SCHELISGER, S. y KINZER, S. (1987); Fruta amarga. La CIA en Guatemala. México: Siglo XXI.

SCHIRMER, J. (1998); Las intimidades del proyecto político militar en Guatemala. Guatemala: FLACSO

SECURITY ASSISTANCE MONITOR (2014); http://www.securityassistance.org/ latin-america-and-caribbean/data/country/trainee/country/2008/2015/ is_all/

SMITH, A. (2007); "Introduction: The revolution will not be funded", en INSITE! The revolution will not be funded. Cambridge: INSITE! Women of color against violence-South End Press.

SOLLIS, P. (1995); "Partners in Development? The State, Nongovernmental Organizations and the UN in Central America", en Third World Quarterly, 16, 3 (September), pp. 525-542.

STREETER, S. (2006); "Nation-Building in the land of eternal counter-insurgency: Guatemala and the contradictions of the Alliance for Progress", en Third World Quarterly, 27, 1, p. 61.

TEIL, J. (2010); "Las incestuosas relaciones de las ONG con Estados y transnacionales”, en Rebelión. http://www.rebelion.org/noticia.php?id=100397 (13 de febrero).

TORRES RIVAS, E. (2006); "Guatemala: desarrollo, democracia y los acuerdos de paz", en Revista Centroamericana de Ciencias Sociales, 3, 2, pp. 11-48.

UDEFEGUA (2014); “El acompañante”. Informe, septiembre de 2014. http://www. plazapublica.com.gt/sites/default/files/informe_udefegua_septiembre.pdf

UDEFEGUA / El observador (2010); "Situación de defensoras y defensores de Derechos Humanos viviendo en el ámbito rural de Guatemala”. Guatemala.

WRIGHT MILLS, Ch. (1978); La élite del poder. México: FCE. 